\title{
Analisis Kepuasan Peternak Plasma terhadap Kinerja Kemitraan Ayam Pedaging di Kabupaten Kampar Provinsi Riau
}

\author{
E. Irawati ${ }^{1 *}$, D. Fitra ${ }^{1}$, \& I. Kantra ${ }^{2}$ \\ ${ }^{1}$ Program Studi Peternakan, Fakultas Pertanian dan Peternakan, UIN Sultan Syarif Kasim \\ ${ }^{2}$ Alumni Program Studi Peternakan, Fakultas Pertanian dan Peternakan, \\ UIN Sultan Syarif Kasim \\ JL. H. R. Soebrantas KM. 15 Tuah Madani, Kec. Tampan, Kota Pekanbaru Riau \\ *Email : eviirawati2013@gmail.co.id
}

(Diterima : 06 Januari 2020; Disetujui : 03 Maret 2020)

\begin{abstract}
The plasma farmer assessment of the company is very important in supporting the sustainability of the partnership relationship. The index of satisfaction is the difference between perceived performance and expectations. The purpose of this study is the evaluation and analysis of chicken business and the measurement of the Customer Satisfactory Indexs (SCI) of plasma farmers in partnership in Kampar Regency, Riau Province. This research is a descriptive study using survey research methods on plasma farmers who partner with poultry companies. It consists of 30 plasma farmers in partnership with foreign capital companies, 10 plasma farmers in partnership with multi-national companies and 6 plasma farmers in partnership with local companies, which were taken by purposive sampling design. Likert scale is used to describe the characteristics of farmers, business characteristics and variable indexes of satisfaction with company performance. The dominant characteristics of broiler partnership plasma farmers in Kampar Regency were: successful broiler farming $>4$ years, have partnered for $>2$ years, the reason for partnering to want a client, get sources of information directly from the partnership company, chicken farming age 35-36 days with harvest weight $1.7-1.8 \mathrm{~kg}$ and mortality $<3 \%$. The conclusion of this study is the Customer Satisfaction Index (CSI) of foreign capital company partnership services of $73.38 \%$ (satisfied), multi-national company partnerships of $74.08 \%$ (satisfied). While local company partnerships had a CSI of $57.66 \%$ or neutral/ordinary criteria.
\end{abstract}

Keywords: customer satisfaction index, partnership, plasma farmer characteristic.

\section{PENDAHULUAN}

Kemitraan merupakan salah satu usaha pembinaan untuk memberdayakan peternak kecil dengan bekerja sama dengan perusahaan, terutama dalam penyediaan sarana prasarana peternakan. Hal ini diatur dalam Undangundang Peternakan dan Kesehatan Hewan Pasal 31 ayat 1 bahwa peternak dapat melakukan kemitraan usaha budidaya ternak berdasarkan perjanjian yang saling menguntungkan dan berkeadilan (Fitriza et al., 2012). Kedua belah pihak bekerjasama dalam kemitraan memiliki posisi yang setara berdasarkan peran masing-masing, agar dapat memberikan keuntungan yang adil bagi kedua belah pihak, kenyataannya pihak perusahaan inti terlalu pegang kendali dan mendominasi, sehingga sering terjadi ketidakadilan.

Sebagian besar pola kemitraan usaha peternakan ayam pedaging yang dilaksanakan adalah dengan pola inti plasma, yaitu kemitraan antara peternak dengan perusahaan mitra. Dimana peternak mitra bertindak sebagai plasma, sedangkan perusahaan mitra sebagai inti. Pada pola inti plasma kemitraan ayam ras yang berjalan selama ini, perusahaan mitra menyediakan sarana produksi peternakan (sapronak) berupa : Day Old Chick (DOC), pakan, obat-obatan/vitamin, bimbingan teknis dan memasarkan hasil, sedangkan plasma menyediakan kandang dan tenaga kerja.

Banyak perusahaan kemitraan ayam pedaging yang telah beroperasi di Provinsi Riau umumnya dan Kabupaten Kampar khususnya. Perusahaan multinasional dengan basis modal asing (PMA) seperti PT. Charoen Pokpand Indonesia, PT. Malindo dan PT. Gold Coin. Perusahaan nasional seperti PT. Japfa dan PT. Sabas, selain itu juga ada perusahaan kemitraan yang bersifat lokal yang beroperasi di wilayah Riau saja seperti CV. Gunung Mas, Riau Feed Centre dan Prada Makmur Sejahtera. Kabupaten Kampar memiliki populasi ayam pedaging terbesar di Provinsi Riau. Dari 48.859.930 ekor populasi ayam ras pedaging di Provinsi Riau tahun 2018, lebih dari 17 juta ekor ada di Kabupaten Kampar (Ditjen PKH, 2018). Data populasi ayam pedaging ini didominasi oleh kemitraan ayam pedaging, baik perusahaan modal asing, nasional ataupun lokal.

Penilaian peternak terhadap kinerja perusahaan merupakan hal yang sangat penting dalam menjaga kesinambungan hubungan kemitraan. Penilaian oleh peternak akan berbeda-beda karena peternak plasma 
memiliki latar belakang pendidikan, usia dan pengalaman yang berbeda-beda. Kepuasan pelanggan adalah perasaan senang atau kecewa seseorang sebagai hasil perbandingan antara prestasi atau produk yang dirasakan dan diharapkan. Tingkat kepuasan merupakan fungsi dari perbedaan antara kinerja yang dirasakan dengan harapan. Apabila kinerja di bawah harapan, maka pelanggan akan kecewa, bila kinerja sesuai dengan harapan, pelanggan akan puas, sedangkan bila kinerja melebihi harapan, pelanggan akan sangat puas.

Harapan pelanggan dapat dibentuk oleh pengalaman masa lampau, komentar dari kerabatnya serta janji dan informasi pemasar dan saingannya. Pelanggan yang puas akan setia lebih lama, kurang sensitif terhadap harga dan memberi komentar yang baik tentang perusahaan (Dwiwinarsih, 2009). Perumusan permasalahannya adalah, mengingat banyaknya perusahaan yang membuka kesempatan untuk bermitra dengan peternak, yang pada akhirnya tidak menutup kemungkinan terjadinya gesekan akibat persaingan. Oleh karena itu, perlu upaya mempertahankan loyalitas peternak agar tidak keluar dari kemitraan yang dijalankan perusahaan. Tujuan penelitian ini adalah mengevaluasi dan menganalisis karakteristik peternak plasma dan mengukur Customer Satisfactory Indexs (SCI) peternak plasma yang melakukan kemitraan di Kabupaten Kampar Provinsi Riau.

\section{MATERI DAN METODE}

Penelitian dilakukan di Kabupaten Kampar pada bulan September-Desember 2018. Pemilihan lokasi dan sampel peternak dilakukan secara sengaja (purposive sampling), dengan pertimbangan bahwa Kabupaten Kampar memiliki populasi ayam pedaging terbesar dan lokasi peternak yang mudah dijangkau. Kriteria sampel yang digunakan adalah peternak plasma yang telah bermitra minimal 1 periode dan memiliki populasi minimal 5.000 ekor ayam pedaging. Sampel juga dibedakan atas tingkatan perusahaan kemitraan, yaitu penanaman modal asing (PMA), multinasional dan lokal. Terdapat 46 sampel peternak plasma yang terpilih, dengan rincian :

30 Peternak plasma kemitraan perusahaan modal asing, selanjutnya disebut KMA.

10 Peternak plasma kemitraan perusahaan multi nasional atau $\mathrm{KMN}$.

6 Peternak plasma kemitraan perusahaan lokal atau KLK.

Penelitian ini merupakan penelitian deskriptif menggunakan metode penelitian survei pada peternak plasma yang bermitra dengan perusahaan peternakan. Penelitian survei adalah pengumpulan data primer dengan cara melakukan wawancara atau tanya jawab dengan responden. Pertanyaan yang diajukan kepada responden dilakukan menggunakan kuisioner. Data yang diperoleh kemudian dikumpulkan, disusun, ditabulasi dan dideskripsikan.

Tabel 1. Daftar atribut kuisioner penelitian

\begin{tabular}{clll}
\hline Periode & No & \multicolumn{1}{c}{ Atribut } & Dimensi Kualitas Pelayanan \\
\hline & 1 & Penerapan harga kontrak DOC & Assurance (jaminan) \\
& 2 & Kualitas DOC & Tangible (bukti nyata) \\
Pelayanan & 3 & Harga kontrak pakan & Tangible (bukti nyata) \\
Sarana & 5 & Kualitas pakan & Tangible (bukti nyata) \\
Produksi & 6 & Harga obat dan vaksin & Tangible (bukti nyata) \\
& 7 & Jadwal pengiriman sarana produksi & Tangible (bukti nyata) \\
& 8 & Assurance (jaminan) \\
\hline & 9 & Pelayanan dan materi bimbingan & Empathy (empati) \\
Pelayanan & 10 & Penerapan standar produksi & Assurance (jaminan) \\
Teknis & 11 & Kesesuaian waktu panen & Reliability (dapat dipercaya) \\
Budidaya & 12 & Respon terhadap segala keluhan & Responsiveness (ketanggapan) \\
& 13 & Kesesuaian harga output/panen & Assurance (jaminan) \\
Pelayanan & 14 & Pemberian bonus & Reliability (dapat dipercaya) \\
Pascapanen & 15 & Pemberian kompensasi & Reliability (dapat dipercaya) \\
\hline Sumber : Kusumah (2008). & & &
\end{tabular}

Instrumen penelitian yang digunakan adalah kuisioner. Petanyaan-pertanyaan yang diajukan berkaitan dengan atribut-atribut yang menjadi perhatian peternak plasma, 
baik itu atribut produk maupun atribut jasa. Pengukuran tingkat kepuasan menggunakan skala untuk mengurangi subjektivitas responden (Sumarwan, 2003). Penggunaan skala juga dimaksudkan untuk mempermudah penjabaran tentang tingkat kepentingan dan tingkat kinerja dari masing-masing atribut. Kuisioner dibuat berdasarkan lima dimensi kualitas pelayanan yaitu reliability, responsiveness, assurance, emphaty, dan tangibles. Atribut kuisioner penelitian dapat dilihat pada Tabel 1.

Skala likert digunakan untuk mendeskripsikan sebagian karakteristik peternak, karakteristik usaha dan variabel tingkat kepuasan terhadap kinerja perusahaan kemitraan ayam pedaging di Kabupaten Kampar, digunakan skala likert dengan rumus :

$$
\mathrm{RS}=\frac{\text { ST-SR }}{\mathrm{BS}}-0,01 \quad \text { (Kusumah, 2008) }
$$

Keterangan:

$$
\begin{aligned}
& \text { RS }=\text { Rentang Skala } \\
& \text { ST }=\text { Skala Tertinggi } \\
& \text { SR }=\text { Skala Terendah } \\
& \text { BS }=\text { Banyak Skala }
\end{aligned}
$$

Customer Satisfaction Index (CSI) atau indeks kepuasan pelanggan digunakan untuk mengetahui tingkat kepuasan peternak plasma secara keseluruhan. Metode pengukuran Customer Statisfaction Index meliputi beberapa tahapan (Kusumah, 2008), sebagai berikut:

1. Menentukan Mean Important Score (MIS) dan Mean Statisfaction Score (MSS),

Nilai ini diperoleh dari rata-rata kepentingan dan kinerja yaitu:

$$
\text { MIS }=\frac{\sum_{i}^{n}=1 Y i}{n} \text { dan MSS }=\frac{\sum_{i}^{n}=1 X i}{n}
$$

Dimana:

$\mathrm{n}$ = Jumlah responden

$\mathrm{Yi}=$ Nilai harapan indikator ke-i

$\mathrm{X} \mathrm{i}=$ Nilai kinerja indikator ke-i

Lama Beternak (\%)

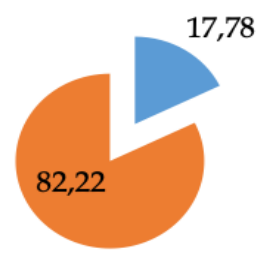

$-<4$ tahun

단 tahun
2. Menentukan Weight Factors (WF),

Bobot ini merupakan persentase nilai MIS per indikator terhadap total MIS seluruh indikator, yaitu:

$$
\begin{aligned}
& \mathrm{WF}=\frac{M I S i}{\sum_{i=1}^{p} M I S i} \times 100 \% \\
& \text { Dimana: } \\
& \mathrm{P}=\text { Jumlah atribut harapan. }
\end{aligned}
$$

3. Menentukan Weight Score (WS),

Bobot ini merupakan perkalian antara WF dengan MSS, yaitu:

$$
\text { WS }=\text { WFi } \times \text { MSSi }
$$

4. Menentukan Customer Satisfaction Index (CSI), yaitu:

$$
\mathrm{CSI}=\frac{\sum_{i=1}^{p} W S i}{H S} \times 100 \%
$$

\section{Dimana:}

$$
\begin{aligned}
\mathrm{HS}= & \text { Skala maksimun (Highest Scale) yang } \\
& \text { digunakan. }
\end{aligned}
$$
berikut :

Hasil CSI tersebut memiliki arti sebagai

$$
\begin{aligned}
& 0,00-0,34=\text { Tidak Puas } \\
& 0,35-0,50=\text { Kurang Puas } \\
& 0,51-0,65=\text { Cukup Puas } \\
& 0,66-0,80=\text { Puas } \\
& 0,81-1,00=\text { Sangat Puas }
\end{aligned}
$$

\section{HASIL DAN PEMBAHASAN}

\section{Karakteristik Usaha Ternak}

\section{Lama beternak dan bermitra}

Sebagian besar peternak plasma ayam pedaging dari ketiga tingkatan perusahaan kemitraan di Kabupaten Kampar telah memiliki pengalaman beternak diatas 4 tahun atau sekitar $82,22 \%$. Sedangkan sekitar $71,11 \%$ peternak telah bermitra diatas 2 tahun. Untuk lebih jelasnya dapat dilihat pada Gambar 1.

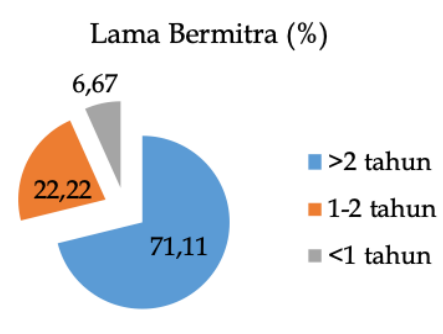

Gambar 1. Persentase responden berdasarkan lama beternak dan bermitra. 
Jauh sebelum kemitraan ayam pedaging masuk di Kabupaten Kampar, sebagian besar peternak sudah mlakukan budidaya ayam secara mandiri. Data diatas dapat menunjukkan lama beternak dan bermitra bervariasi, mulai dibawah 1 tahun sampai lebih dari 4 tahun. Hal ini sejalan dengan penelitian Arum et al. (2017), yang menyatakan pengalaman beternak peternak pola kemitraan mulai 1 tahun sampai 6 tahun.

Umur kemitraan menandakan sebuah kepuasan, semakin lama peternak bermitra membuktikan loyalitas kepada perusahaan inti. Karena menurut Dwiwinarsih (2009) menyatakan pelanggan yang puas akan setia lebih lama, kurang sensitif terhadap harga dan akan memberi komentar yang baik tentang perusahaan. Akan tetapi, apabila kinerja perusahaan di bawah harapan, maka peternak akan kecewa, berhenti bermitra dan akan mencari perusahaan kemitraan lain.

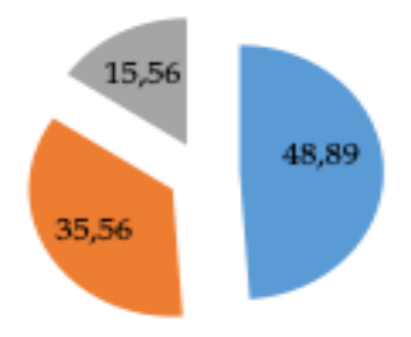

Semakin lama pengalaman beternak dan bermitra juga diasumsikan menjadi salah satu faktor keberhasilan dan keberlanjutan usaha ayam pedaging. Hal ini tidak sejalan dengan pendapat Nahreini et al. (2016) yang menyatakan faktor pengalaman berhubungan negatif dengan persepsi peternak terhadap pelaksanaan kemitraan.

\section{Alasan utama bermitra}

Alasanutamayang menyebabkan peternak memilih bermitra adalah ingin mempunyai penghasilan sebanyak $48,89 \%$. Hal ini selaras dengan variabel mata pencaharian, dimana sebagian besar peternak mengandalkan usaha ternak ayamnya sebagai mata pencaharian utama atau usaha pokok. Alasan lain bermitra ingin mendapatkan kemudahan dalam memperoleh sarana produksi sebanyak 35,56\% dan sisanya yaitu peternak dengan alasan sistem birokrasi kemitraan yang lebih mudah dengan persentase $15,56 \%$. Untuk lebih jelasnya dapat dilihat pada Gambar 2.

$$
\begin{aligned}
& \text { " Ingin punya penghasilan } \\
& \text { " Kemudahan dalam memperoleh } \\
& \text { sarana produksi } \\
& \text { = Sistem birokrasi yang lebih mudah }
\end{aligned}
$$

Gambar 2. Persentase responden berdasarkan alasan bermitra (\%).

Alasan bermitra pada hasil penelitian ini sejalan dengan penelitian Lestari (2009) yang menyatakan untuk meningkatkan keuntungan menjadi alasan utama bermitra sekitar 58\%. Berdasarkan Kepres Nomor 22 Tahun 1990, kemitraan diharapkan dapat menjadi solusi untuk merangsang tumbuhnya peternak di Indonesia terutama bagi peternak rakyat yang kepemilikan modalnya relatif kecil. Walaupun dalam pelaksanaannya belum sesuai dengan tujuan kemitraan tersebut.

\section{Sumber informasi mengenai kemitraan}

Informasi mengenai kemitraan sebagian besar peternak mendapatkannya langsung dari pihak kemitraan itu sendiri yaitu sebanyak $44,44 \%$, warga yang ikut beternak $35,56 \%$, teman/rekan kerja $8,89 \%$ dan yang uniknya pada pengamatan ini sekitar $11,11 \%$ informasi kemitraan mereka mengetahui dengan sendirinya. Untuk lebih jelasnya dapat dilihat pada Gambar 3.

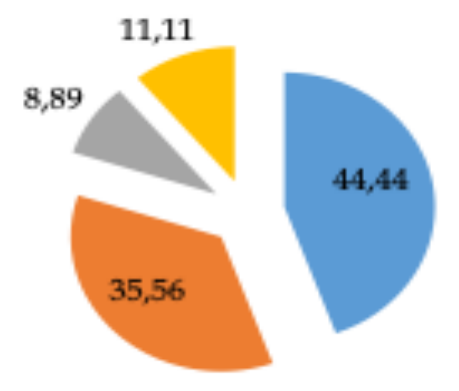

Gambar 3. Persentase responden berdasarkan sumber informasi (\%). 
Bervariasinya sumber informasi ini dipengaruhi oleh semakin berkembangnya teknologi informasi, terutama media sosial dan elektronik. Semua orang dapat memperoleh informasi dengan mudah hanya dengan berselancar didunia maya melalui gadgetnya. Penelitian serupa juga membuktikan sumber informasi mengenai kemitraan ayam broiler didapatkan langsung dari pihak perusahaan sekitar 48\% (Lestari, 2009). Informasi terkait kemitraan secara langsung biasanya melalui tenaga marketing yang umumnya disebut dengan Technical Service (TS) atau juga berasal dari Petugas Peyuluh Lapang (PPL), dimana mereka direkrut oleh perusahaan inti untuk memberikan pendampingan kepada peternak plasma.

\section{Pengetahuan dan pemahaman tantang peraturan kemitraan}

Hasil pengamatan menunjukkan bahwa keseluruhan atau sebanyak $100 \%$ peternak tahu dan paham tentang peraturan kemitraan yang diberlakukan oleh perusahaan kemitraan ayam pedaging di wilayah Kabupaten Kampar. Hal ini diasumsikan bahwa SOP pengajuan kemitraan yang berlaku di masing- masing perusahaan inti berjalan dengan baik. Perusahaan inti berhubungan secara langsung dengan peternak plasma melalui perjanjian kerjasama (kemitraan) secara tertulis walaupun Dewi et al. (2014) menyatakan tanda tangan kontrak kemitraan ayam pedaging secara umum dilakukan tidak dihadapan notaris. Konsekuensi dari tanda tangan inilah dapat diartikan peternak mengetahui dan memahami akan peraturan kemitraan.

\section{Umur panen}

Ayam yang dipanen pada umur 35-36 hari adalah umur panen terbanyak dalam pengamatan ini dengan $84,44 \%$, sedangkan umur panen 30-32 hari sebanyak 8,89\% dan sisanya $6,67 \%$ ayam dipanen diumur $33-34$ hari. Sebenarnya umur panen ini sudah termasuk kedalam kontrak perjanjian kemitraan, tetapi yang menjadi permasalahan seringkali adalah kandang dengan lokasi agak jauh dipanen belakangan, walaupun sudah masuk umur panen. Hal ini diperparah lagi jika perusahaan memiliki kandang mitra dengan umur panen bersamaan sedangkan permintaan (demand) daging ayam dipasaran kurang atau lesu.

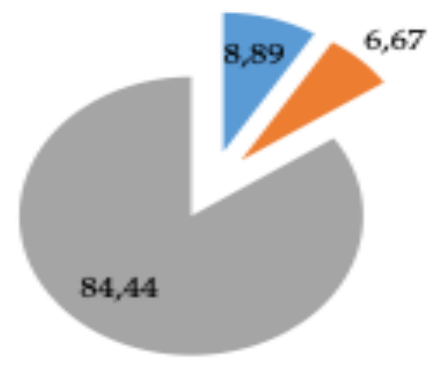

= $30-32$

घ3-34

$=35-36$

Gambar 4. Persentase responden berdasarkan umur panen (\%).

Keputusan panen terletak pada peternak, jika peternak melihat bobot ayam telah menghasilkan keuntungan atau jika peternak merasa keadaan kandang sangat padat, maka peternak juga bisa meminta untuk panen. Bowo (2017) menyatakan tidak jarang waktu pemamenan berubah karena situasi dan kondisi saat pemanenan seperti bobot yang diinginkan oleh pembeli/broker tidak sesuai, harga pasar ataupun penundaan dari perusahaan sendiri.

\section{Bobot badan ayam siap panen}

Berdasarkan hasil pengamatan sebagian besar atau sekitar 80,00\% ayam dipanen oleh pihak kemitraan pada bobot badan 1,7-1,8 kg/ekor. Karena pada kisaran bobot badan tersebut permintaan daging ayam lebih besar selain pertimbangan ekonomis dari perusahaan kemitraan itu sendiri. Peternak juga memanen ayamnya pada kisaran 1,5-1,6 $\mathrm{kg}$ /ekor sebanyak $17,78 \%$ dan sisanya $2,22 \%$ menyatakan dipanen dengan bobot kecil yakni 1,3-1,4 kg/ekor. Untuk lebih jelasnya dapat dilihat pada Gambar 5.

Variasi bobot panen ini terjadi kalau permintaan daging ayam tinggi dan harga cukup bagus, maka pertimbangan segera dipanen menjadi pilihan atau teridentifikasi sakit sehingga dipanen untuk menghindari kerugian. Faktor-faktor diatas akan menjadi penentu waktu panen walaupun bobotnya belum sesuai. Sejalan dengan penelitian Dewi et al (2014) yang menyatakan bobot panen ayam kemitraan berkisar 1,6-2,45 kg. 


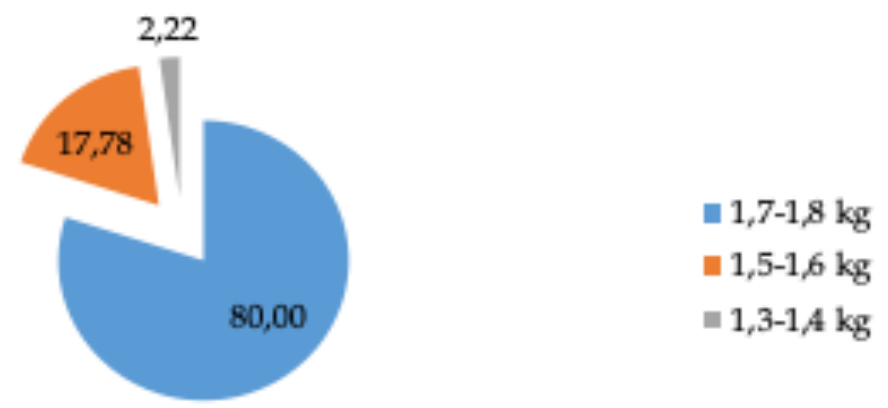

Gambar 5. Presentase responden berdasarkan berat ayam siap panen (\%).

\section{Mortalitas per periode}

Ayam pedaging pola kemitraan di Kabupaten Kampar sebanyak 42,22\% memiliki tingkat mortalitas $<3 \%$, artinya angka ini masih dalam kategori kewajaran. Management guidance PT. Charoen Pokphand memberikan toleransi kematian dalam budidaya ayam pedaging maksimal 3\%, sedangkan sisanya ayam pedaging yang dipelihara peternak responden memiliki tingkat kematian $>3 \%$ bahkan sampai
$8 \%$, hal ini menandakan masih buruknya tatalaksana budidaya sehingga menyebabkan kematian lebih banyak. Banyak faktor yang menjadi penyebab tingginya angka mortalitas, sering di lapangan ditemui buruknya manajemen pemeliharaan, kebersihan dan sanitasi, brooding yang tidak sesuai bahkan tak sedikit yang diakibatkan oleh penyakit. Untuk lebih jelasnya dapat dilihat pada Gambar 6.

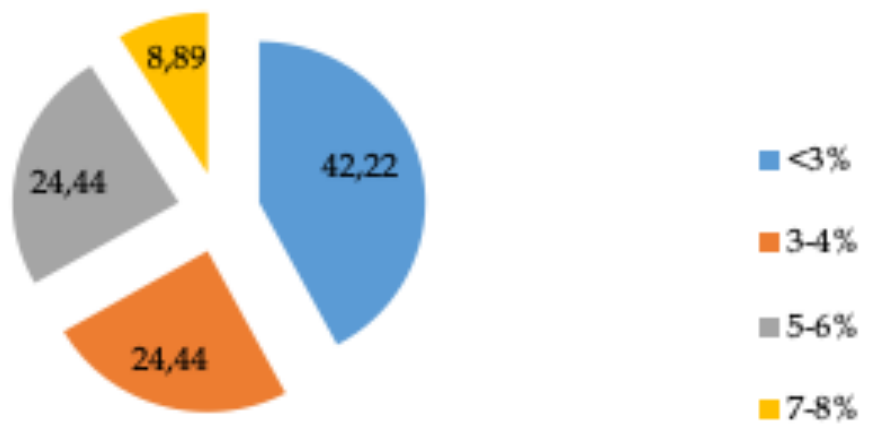

Gambar 6. Persentase responden berdasarkan mortalitas per periode (\%).

\section{Customer Satisfaction Index (CSI)}

Kepuasan adalah respon akan terpenuhinya ekspektasi konsumen. Itu adalah sebuah pertimbangan fitur dari sebuah produk atau jasa memberikan sebuah tingkat kenikmatan terpenuhinya ekspektasi konsumen (Oliver, 1996).

Pengukuran ini dilakukan untuk mengetahui seberapa besar harapan peternak plasma dapat dipenuhi oleh perusahaan inti. Metode Customer Satisfaction Index (CSI) digunakan untukmenentukan tingkatkepuasan secara keseluruhan dengan pendekatan yang mempertimbangkan tingkat kepentingan dari atribut-atribut kemitraan yang diukur.

Berdasarkan perhitungan nilai Customer Satisfaction Index (CSI) pada Tabel 2, nilai kinerja pelayanan yang telah dilakukan oleh pihak Kemitraan Perusahaan Modal Asing (KMA) adalah sebesar 0,7383 atau 73,38\% dan Kemitraan Perusahaan Multi Nasional (KMN) adalah sebesar 0,7408 atau 74,08. Nilai dari dua kemitraan ini termasuk kedalam kriteria puas, Hal ini berarti sebagian besar peternak plasma merasa puas dengan pelayanan yang diberikan oleh KMA dan KMN. Setidaknya 15 fitur pelayanan yang diukur mengindikasikan hasil yang memuaskan. Atas dasar tersebut pihak kemitraan untuk masa yang akan datang perlu mempertahankan kualitas pelayanan yang diberikan. Perolehan nilai CSI pada penelitian ini lebih baik dibandingkan dengan penelitian Yudhabaskara (2017) terhadap peternak mitra Duta Technovet Bogor, dimana nilai CSI yang diperoleh hanya $70,65 \%$. 
Tabel 2. Perhitungan costumer satisfaction index (CSI)

\begin{tabular}{lccc}
\hline \multicolumn{1}{c}{ Atribut } & KMA & KMN & KLK \\
\hline Penerapan harga kontrak DOC & 0,231 & 0,247 & 0,157 \\
Kualitas DOC & 0,191 & 0,240 & 0,159 \\
Harga kontrak pakan & 0,239 & 0,247 & 0,161 \\
Kualitas pakan & 0,234 & 0,246 & 0,146 \\
Harga obat dan vaksin & 0,235 & 0,228 & 0,203 \\
Kualitas obat dan vaksin & 0,238 & 0,222 & 0,261 \\
Jadwal pengiriman sarana produksi & 0,244 & 0,215 & 0,231 \\
Frekuensi bimbingan teknis & 0,255 & 0,241 & 0,270 \\
Pelayanan dan materi bimbingan & 0,246 & 0,234 & 0,272 \\
Penerapan standar produksi & 0,219 & 0,215 & 0,181 \\
Kesesuaian waktu panen & 0,273 & 0,281 & 0,186 \\
Respon terhadap segala keluhan & 0,270 & 0,260 & 0,188 \\
Kesesuaian harga output / panen & 0,282 & 0,288 & 0,176 \\
Pemberian bonus & 0,262 & 0,267 & 0,170 \\
Pemberian kompensasi & 0,273 & 0,274 & 0,122 \\
\hline \multicolumn{1}{c}{ Total } & 3,692 & 3,704 & 2,883 \\
\hline
\end{tabular}

Keterangan : Pengolahan data kuesioner 2018.

Nilai kinerja pelayanan yang telah dilakukan oleh pihak Kemitraan Lokal (KLK) adalah 0,5766 atau $57,66 \%$ yang mana nilai ini termasuk kedalam kriteria netral/cukup. Hal ini menjelaskan sebagian besar peternak plasma dari Kemitraan Lokal belum puas akan kinerja pelayanannya, sehingga kedepan perlu diperbaiki atau ditingkatkan. Perusahaan diharapkan agar tidak cepat merasa puas dan terus berusaha meningkatkan kepuasan peternak plasmanya. Beberapa atribut yang dikeluhkan peternak plasma adalah kualitas DOC, harga kontrak pakan, kesesuaian waktu panen serta pemberian bonus dan kompensasi.

\section{KESIMPULAN}

Berdasarkan hasil diatas, maka diperoleh beberapa kesimpulan, antara lain karakteristik dominan peternak plasma kemitraan ayam pedaging di Kabupaten Kampar adalah : sudah berpengalaman beternak ayam pedaging $>4$ tahun, sudah bermitra selama $>2$ tahun, alasan bermitra ingin punya penghasilan, mendapatkan sumber informasi langsung dari perusahaan kemitraan, umur panen ayam 3536 hari dengan bobot panen 1,7-1,8 dan tingkat mortalitas $<3 \%$.

Customer Satisfaction Index (CSI) dari pelayanan kemitraan perusahaan modal asing adalah sebesar 73,38\% (Puas), kemitraan perusahaan multi nasional adalah sebesar $74,08 \%$ (Puas). Sedangkan kemitraan perusahaan lokal memiliki CSI sebesar 57,66\% atau kriteria netral/cukup.

Kemitraan perusahaan modal asing dan kemitraan perusahaan multi nasional disarankan agar mempertahankan kinerja pelayanannya, sedangkan untuk kemitraan perusahaan lokal agar segera memperbaiki atau meningkatkan kinerja pelayanannya, agar bisa bertahan dan memperoleh peternak yang loyal.

\section{UCAPAN TERIMA KASIH}

Ucapan terima kasih kepada Direktorat Pendidikan Tinggi Islam Kementerian Agama Republik Indonesia yang telah memberikan hibah penelitian kluster individu.

\section{DAFTAR PUSTAKA}

Arum, K. T, E. R. Cahyadi, \& A. Basith. 2017. Evaluasi kinerja peternak mitra ayam ras pedaging. Jurnal Ilmu Produksi dan Teknologi Hasil Peternakan. 5(2) : 78-83.

Bowo, H. T. 2017. Analisis usaha peternakan ayam ras pedaging dengan pola kemitraan inti plasma (Studi kasus: Peternakan Andi Saputra Kec. Tambang, Kampar). Skripsi. Fakultas Pertanian dan Peternakan. UIN Sultan Syarif Kasim Riau. Pekanbaru.

Direktorat Jenderal Peternakan dan Kesehatan Hewan (Ditjen PKH) Kementerian Pertanian RI. 2018. Statistik Peternakan dan Kesehatan Hewan. https://ditjenpkh.pertanian.go.id. Jakarta. Diakses pada 03 Februari 2020. 
Dewi, P., D. Soejono, \& J. M. M. Aji. 2014. Evaluasi kemitraan usaha ayam ras pedaging di Desa Sidomulyo Kecamatan Silo Kabupaten Jember. Berkala Ilmiah Pertanian. 1(1) : 1-9.

Dwiwinarsih, R. 2009. Analisis Tingkat Kepuasan Konsumen terhadap Pelayanan Bakmi Aisy di Depok. Skripsi. Fakultas Ekonomi. Universitas Gunadarma. Depok. Jawa Barat.

Fitriza, Y. T., F. T. Haryadi, \& S. P. Syahlani. 2012. Analisis pendapatan dan persepsi peternak plasma terhadap kontrak perjanjian pola kemitraan ayam pedaging di Provinsi Lampung. Buletin Peternakan. 36(1) : 57-65.

Kusumah, M. 2008. Analisis Tingkat Kepuasan Peternak Plasma terhadap Pola Kemitraan Tunas Mekar Farm di Kecamatan Nanggung, Kabupaten Bogor. Skripsi. Program Studi Sosial Ekonomi Peternakan. Fakultas Peternakan. Institut Pertanian Bogor. Bogor.

Lestari, M. 2009. Analisis Pendapatan dan Tingkat Kepuasan Peternak Plasma terhadap Pelaksanaan Kemitraan Ayam Broiler Kemitraan PT X di Yogyakarta. Skripsi. Departemen Agribisnis Fakultas Ekonomi dan Manajemen. Institut Pertanian Bogor. Bogor.
Nahraeni, W., S. Masithoh, \& I. Maesarah. 2016. Persepsi Peternak Ayam Pedaging (Broiler) terhadap Kemitraan di Kabupaten Bekasi Provinsi Jawa Barat. Jurnal AgribiSains. 2(2) : 40-51.

Oliver. 1996. Satisfaction: A Behavioral Perpective on The Consumer. The Mc Graw Hill Companies, Inc. New York.

Sumarwan, U. 2003. Perilaku Konsumen Teori dan Penerapan dalam Pemasaran. PT. Ghalia Indonesia. Jakarta.

Yudhabaskara, R. N. 2017. Analisa Tingkat Kepuasan Kemitraan Peternak Plasma terhadap Pelayanan Perusahaan Inti (Kasus di Peternak Mitra Duta Technovet). Skripsi. Departemen Agribisnis. Fakultas Ekonomi dan Manajemen. Institut Pertanian Bogor. Bogor. 